\title{
Effect of Cold Atmospheric Plasma on Ehrlich Carcinoma
}

\author{
M. I. EL Gohary, F. F. EL Aksher, S. A. Ghalab and M. A. \\ Abu Ghazala \\ Physics Department, Faculty of Science, Al-Azhar University, \\ 11884 Cairo, Egypt.
}

\begin{abstract}
R ECENT progress in atmospheric plasma has led to creation of cold plasma with ions temperature close to room temperature. In present study the effects of cold atmospheric plasma jet on Ehrlich Carcinoma (EC) has been revealed. The present study is carried out on three groups of Males Swiss albino mice bearing Ehrlich Carcinoma. Design of suitable plasma source is used for the treatment. Tumors are ablated with a single transdermal cold atmospheric plasma (CAP) treatment. Tumor volume and mice survival parameters are determined. Results indicate that the mechanism of action for cold plasma on cancer cells is due to generation of reactive oxygen species (ROS). This is occurred with possible induction of the apoptosis pathways. The results of this study reveal that the CAP greatly inhibits Ehrlich Carcinoma cells (ECC) growth. This is considered as an advanced new modality for treatment of cancer cells with least side effects.
\end{abstract}

Keywords: Cold plasma, Ehrlich carcinoma and Reactive oxygen species (ROS).

A plasma is an ionized medium that contains numerous active components including electrons and ions, free radicals, reactive molecules, and photons ${ }^{(1,2)}$. Plasma can be categorized as either local thermodynamic (thermal) equilibrium plasma (LTE) or non-local thermodynamic (cold) equilibrium plasma (non-LTE) and it is important to note that an atmospheric plasma jet can be divided in two zones: A central zone or plasma core which is in LTE and a peripheral zone or plasma plume which is in non-LTE.

Nowadays cold atmospheric plasma (CAP) treatments are being investigated for multiple biological applications for example: tissue sterilization, blood coagulation, wound healing, tissue regeneration, dental treatment, and the treatment of various diseases, including cancer $^{(3,4)}$.

Recently, some researchers concerned with plasma in medicine have studied the possible applications in cancer therapy. Some early attempts have shown that plasma exerts antitumor effects on a wide variety of cancer cells. If this method is compared with conventional anticancer therapies, such as ionizing radiation and chemotherapy, plasma can kill cancer cells by triggering apoptosis of cells ${ }^{(5-7)}$. 
This occurs with high efficiency and fewer side-effects on the surrounding healthy cells ${ }^{(8)}$. Treatment of cancer cells with plasma exposes them to reactive oxygen species (ROS) leading to apoptosis of cells at a rapid pace ${ }^{(9)}$.

Ehrlich ascites carcinoma (EAC) is one of the common model example for anticancer agent ${ }^{(10)}$. This type of research was done on males and female Swiss albino mice ${ }^{(11)}$.

The aim of the present work is to study the effect of CAP on Ehrlich tumor. Continuous monitoring for tumor growth is done when mice exposed to treatment.

\section{Materials and Methods}

The present part shows the characteristics of source for treatment of Cancerous cells and the mice classifications. Figure 1, shows the cold atmospheric plasma jet system which is used for treatment.

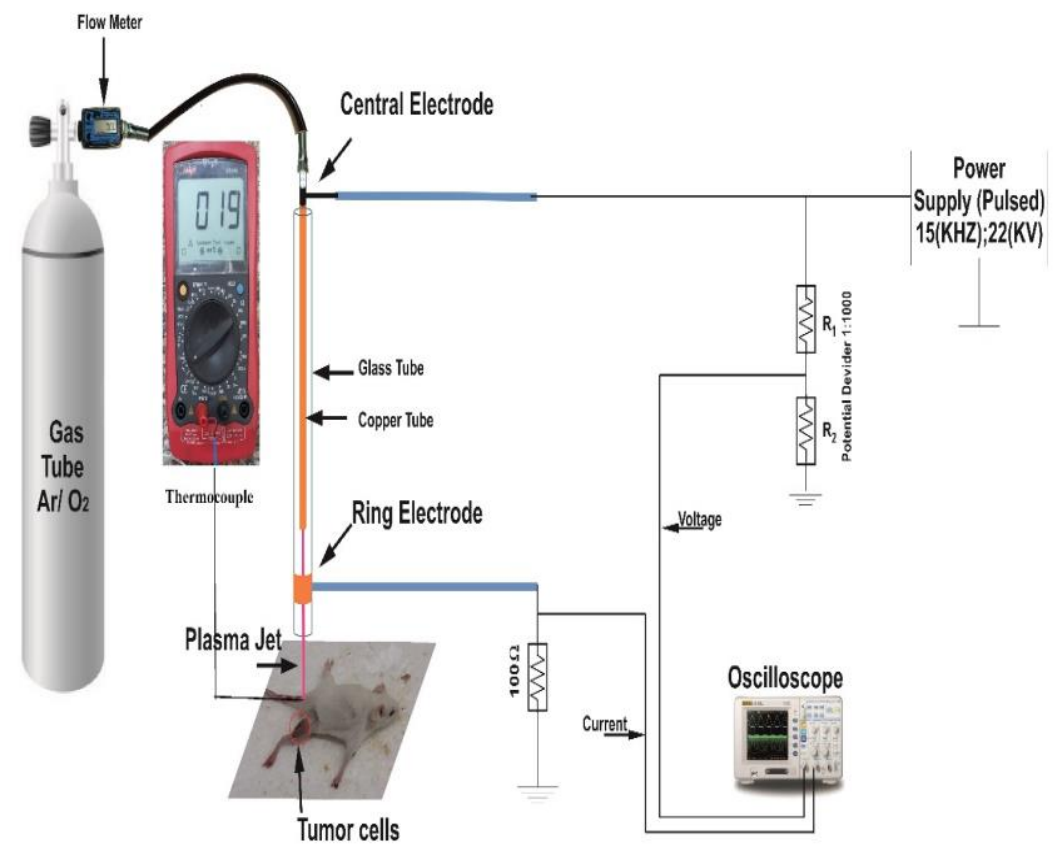

Fig. 1. Aschematic diagram of PCAPJ system for treatment of cancer cells.

The electrical characteristics of the PCAP jet discharge have been studied using the discharge circuit shown in Fig .1. The emitted jet has the following parameters as shown in Table 1.

Egypt. J. Biophys. Biomed. Engng. Vol. 17 (2016) 
TABLE 1. Discharge parameters of PCAP.

\begin{tabular}{|l|c|}
\hline Gas type & Argon \\
\hline Gas flow rate & $41 / \mathrm{min}$ \\
\hline Frequency & $15 \mathrm{kHz}$ \\
\hline Discharge current & $70 \mathrm{~mA}$ \\
\hline Discharge voltage & $4.5 \mathrm{kV}$ \\
\hline Power & $3.4 \mathrm{~W}$ \\
\hline Dose of Plasma for 2 min & $6 \mathrm{~J} / \mathrm{cm}^{2}$ \\
\hline Dose of Plasma for 3 min & $9 \mathrm{~J} / \mathrm{cm}^{2}$ \\
\hline Streamer length & $2.3 \mathrm{~cm}$ \\
\hline Streamer radius & $0.5 \mathrm{~cm}$ \\
\hline
\end{tabular}

Spectroscopic measurements for PCAP.

Figure 2. shows the emitted Argon (Ar) lines and nitrogen $\left(\mathrm{N}_{2}\right)$ bands. Oxygen $(\mathrm{O})$ line at $(777.4 \mathrm{~nm})$ and hydroxyl group $(\mathrm{OH})$ at $(308 \mathrm{~nm})$ are observed due to the presence of argon and air. $\mathrm{OH}$ and $\mathrm{O}$ species are known for their antimicrobial action due to their high oxidation potentials. These data are in agreement with those obtained by García-Alcantara et al. and Dong et al. ${ }^{(12,13)}$.

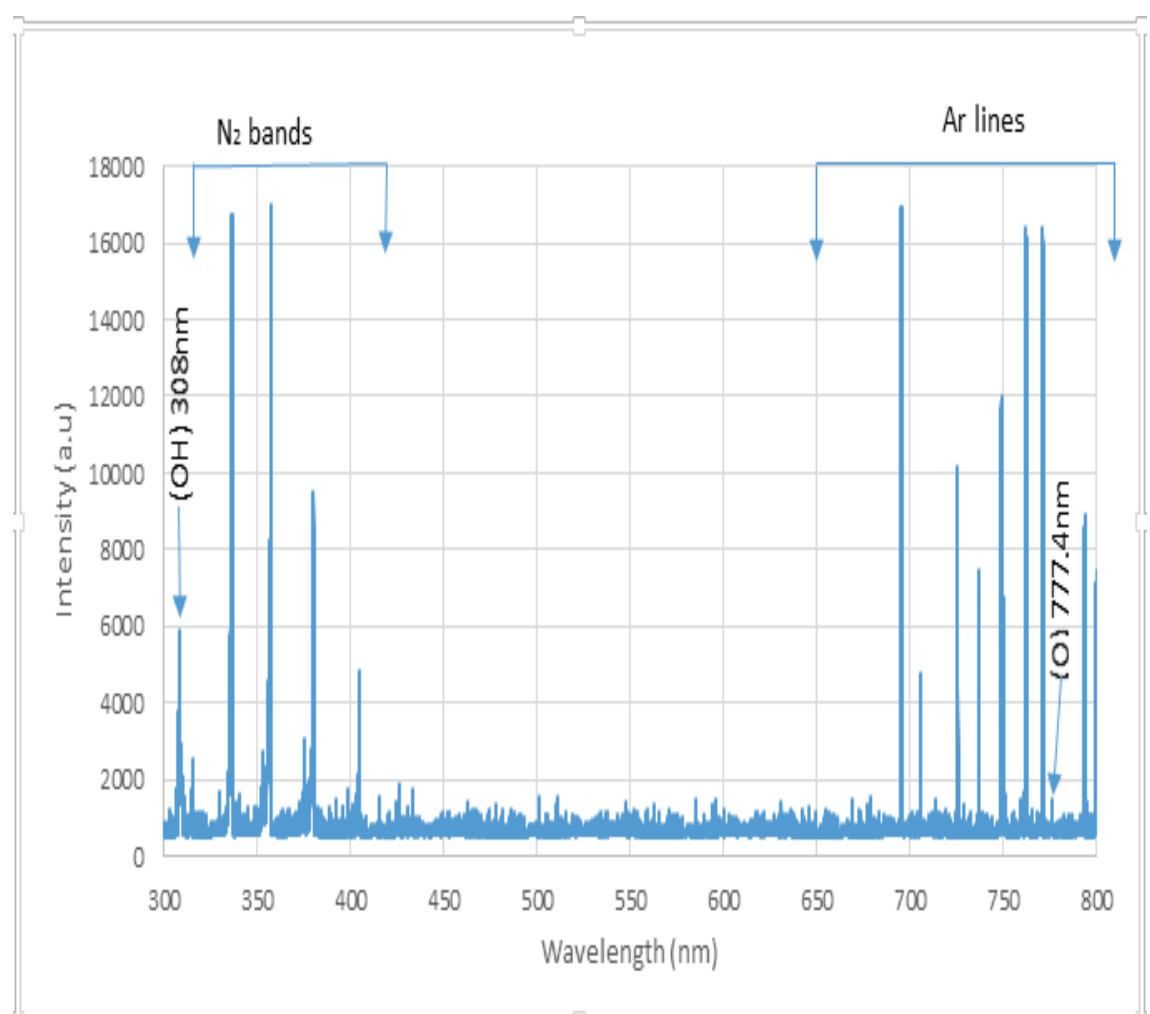

Fig. 2. Emission spectra of Ar plasma jet at $300-800 \mathrm{~nm}$. Applied voltage $=4.5 \mathrm{kV}$, gas flow rate $=41 / \mathrm{m}$ and position of plasma jet $=1 \mathrm{~cm}$.

Egypt. J. Biophys. Biomed. Engng. Vol. 17 (2016) 
Thermal properties along axial jet

Figure 3, indicates the dependence of temperature on the axial distance outside the glass tube which is determined by thermocouple device along the outside discharge at various distances from the end of tube. This temperature is decreasing from about $80^{\circ} \mathrm{C}$ at $0.5 \mathrm{~cm}$ distance to $37^{\circ} \mathrm{C}$ at $2.3 \mathrm{~cm}$ from the end of tube. These results are in good agreement with previously reported data ${ }^{(14)}$.

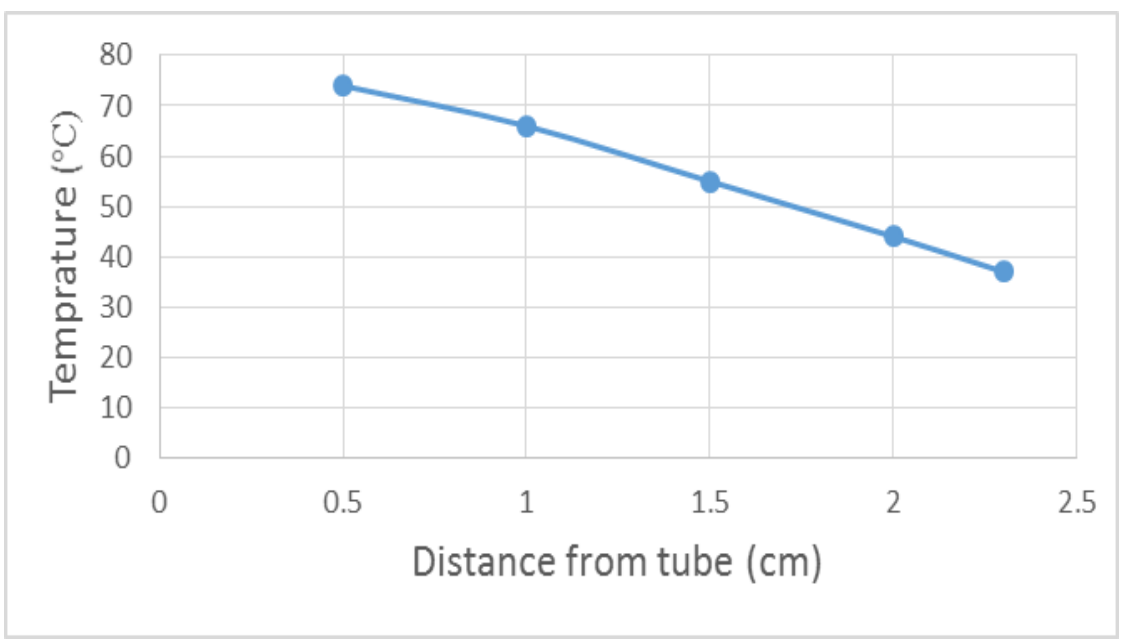

Fig. 3. Dependence of temperature on the axial distance between sensor and the end of tube.

\section{Cell culture and tumor inoculation}

Ehrlich ascites tumor is chosen as a rapidly growing experimental tumor model ${ }^{(15)}$ where various experimental designs for anticancer agents can be applied. Ehrlich ascites carcinoma cells obtained from national cancer institute "NCI", Cairo University. Animals are injected in the right thigh of the hind limb by $0.2 \mathrm{ml}$ from suspension containing $1 \times 10^{6}$ of the Ehrlich carcinoma cells (ECC). A palpable solid tumor mass (about $\geq 100 \mathrm{~mm}^{3}$ ) is developed within 12 days ${ }^{(16,17)}$. Tumor growth is monitored post-inoculation until the desired volume is reached.

Classification of animals

The animals are divided into 3 equal groups of seven mice for each:

Group (1): control or untreated, Ehrlich tumor cells are implanted subcutaneously into the right thigh of the hind limb of mice without exposing to plasma jet.

Group (2): mice with Ehrlich tumor cells are exposed to plasma jet for $2 \mathrm{~min}$, (Flow rate $=4 \mathrm{l} / \mathrm{min}$, applied voltage $=4.5 \mathrm{kV}$, plasma dose $=6 \mathrm{~J} / \mathrm{cm}^{2}$ ).

Group (3): mice with Ehrlich tumor cells are exposed to plasma jet for $3 \mathrm{~min}$, (Flow rate $=4 \mathrm{l} / \mathrm{min}$, applied voltage $=4.5 \mathrm{kV}$, plasma dose $=9 \mathrm{~J} / \mathrm{cm}^{2}$ ).

Egypt. J. Biophys. Biomed. Engng. Vol. 17 (2016) 
Tumor volume estimation

Tumor volume is measured on days 12, 14, 16, 18 until 24 day after implantation of (ECC) using a digital calliper. The following formula is used to calculate the volume of the developed tumor ${ }^{(5)}$.

$$
\text { Tumor volume }\left(\mathrm{mm}^{3}\right)=\mathrm{V}=.52 \times\left(\mathrm{A} \times \mathrm{B}^{2}\right)
$$

where $\mathrm{A}$ is the long axis of tumor, $\mathrm{B}$ is short axis of tumor and $\pi=3.14$. Mice are selected for treatment when the tumor reaches the desired volume. Finally all mice are sacrificed. The tumors are excised for histopathological examination.

\section{Statistical analysis}

Data are presented as mean $\pm \mathrm{SE}$, data are analyzed by using student t-test and difference between the mean of different groups is considered significant at a level of $\mathrm{p}<0.05$.The statistical program applied is Statistical Package for the Social Sciences (SPSS).

\section{Results and Discussion}

The advancement of tumor are followed thoroughly through experimental measurements. Various means of analysis are also performed.

\section{Inhibition of tumor growth by influence of PCAP}

The effect of cold plasma in-vivo, when the cold plasma jet is applied to mice which injected with Ehrlich ascites carcinoma. Figure 4A shows the tumor formed by injection. It is observed that a single cold plasma treatment through overlying skin leads to tumor ablation where tumor volume diminishes and doesn't grow again as shown as Fig. 4B. This procedure is applied on 2 groups, each contains 7 mice. The first group is treated for a period of $2 \mathrm{~min}$ using dose of pulsed cold atmospheric plasma (PCAP) of $6 \mathrm{~J} / \mathrm{cm}^{2}$ and the second one for 3 min using dose of PCAP of $9 \mathrm{~J} / \mathrm{cm}^{2}$.

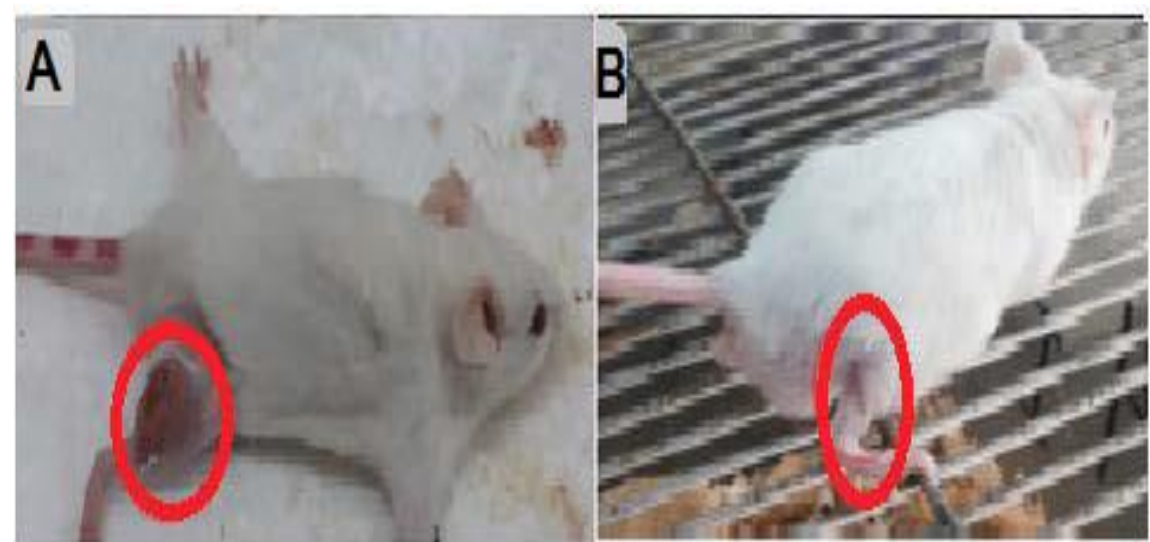

Fig. 4 A. Mice with clear tumor, B. Mice without tumor after treatment.

Egypt. J. Biophys. Biomed. Engng. Vol. 17 (2016) 
As shown in Fig. 5, rates of tumor growth are markedly decreased after cold plasma treatment.

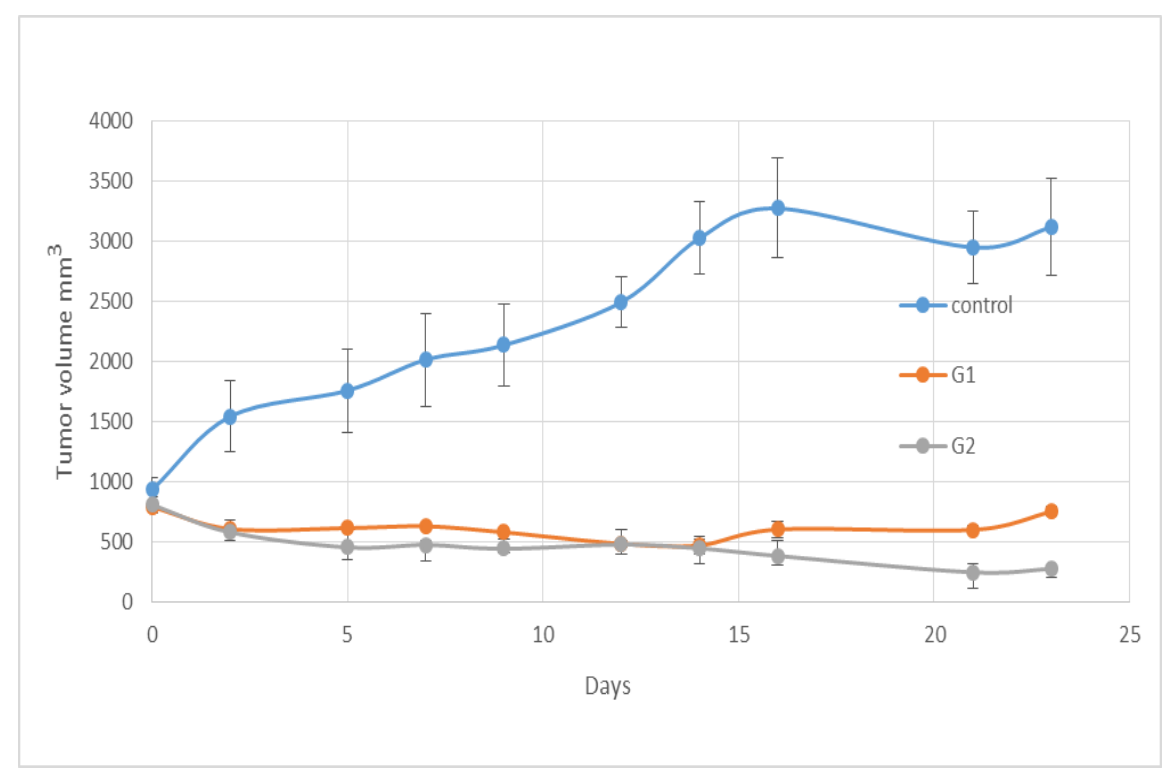

Fig. 5. Effect of PCAPJ on tumor volume.

Table 2 indicates the effect of PCAP on tumor volume. It is noticed that the average tumor volume increases in the control group from $929.6 \pm 100$ to $3116.6 \pm 406 \mathrm{~mm}^{3}$ after 23 days, although the average tumor volume of the first group decreases significantly from $788 \pm 38.5$ to $748 \pm 41 \mathrm{~mm}^{3}$ and the average tumor volume of the second group decrease from $805.9 \pm 71$ to $273 \pm 26.45 \mathrm{~mm}^{3}$ after 23 days. This shows that the inhibition of cancer growth rate increasing by enhancement of dose from 6 to $9 \mathrm{~J} / \mathrm{cm}^{2}$ as found by Dobrynin et al., ${ }^{(18)}$. Table 2 shows that the inhibition of tumor grows percentage is decreasing by $71.9 \%$ for the dose of $6 \mathrm{~J} / \mathrm{Cm}^{2}$ and by 90.1 for $9 \mathrm{~J} / \mathrm{cm}^{2}$.

TABLE 2 . The effect of PCAP on tumor volume decrement.

\begin{tabular}{|c|c|c|c|}
\hline Index & Control & $\begin{array}{c}\text { G1 } \\
\text { Dose }=6 \mathrm{~J} / \mathrm{cm}^{2}\end{array}$ & $\begin{array}{c}\text { G2 } \\
\mathrm{J} / \mathrm{cm}^{2} 9=\text { Dose }\end{array}$ \\
\hline $\begin{array}{c}\text { Mean Tumor volume } \\
.\left(\mathrm{mm}^{3}\right) \text { before treatment }\end{array}$ & $929.5 \pm 100$ & $788 \pm 38.5$ & $805 \pm 71$ \\
\hline $\begin{array}{c}\text { Mean Tumor volume } \\
\left(\mathrm{mm}^{3}\right) \text { after treatment time }\end{array}$ & $3116 \pm 406$ & $748 \pm 41$ & $273 \pm 26.45$ \\
\hline $\begin{array}{c}\text { Inhibition of Tumor } \\
\text { \%Growth }\end{array}$ & - & $71.9 \%$ & $90.1 \%$ \\
\hline
\end{tabular}

Egypt. J. Biophys. Biomed. Engng. Vol. 17 (2016) 
Improvement of survival

Figure 6, Shows the variation of the survival percentage versus of the incubation period of tumor implantation for all groups. The results show that the curve of control group exhibit no animal survival not longer than 24 days but mice exposed to plasma doses of both 6 and $9 \mathrm{~J} / \mathrm{cm}^{2}$ survived for a period of 36 day.

This indicates that there is positive effect of cold plasma jet on both tumor growth and survival period of the experimental animals ${ }^{(5,19)}$.

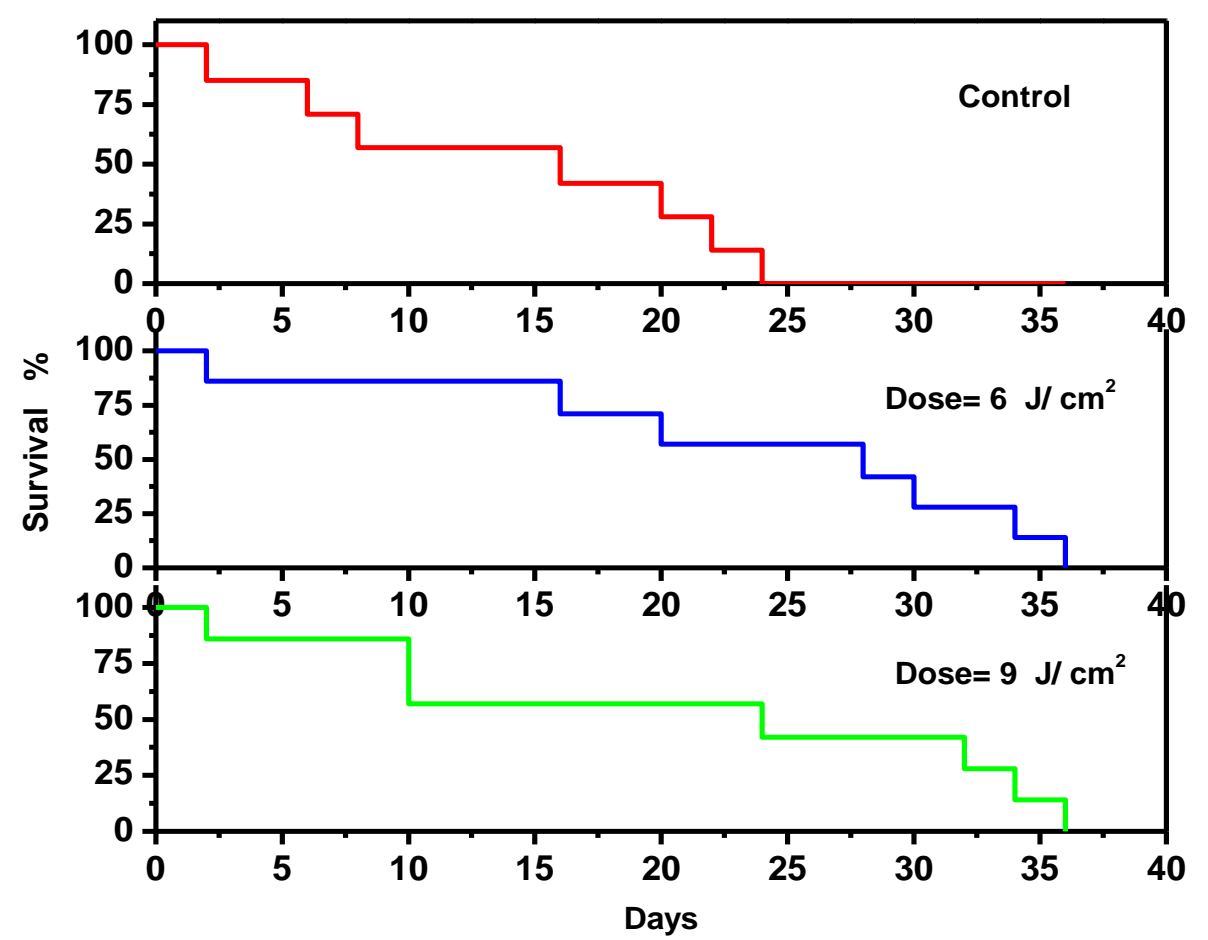

Fig. 6. Effect of PCAPJ on the mice survival .

\section{Discussion}

Sever effect of cold plasma treatment on cancerous tissue in vivo have been observed. Safety plasma treatment for the whole mouse organism and the absence of skin damages are recorded whereas the thermal effects associated with cold plasma are negligible as the results represented in Fig. 4. 
There are many external factors that can induce apoptosis such as short-living reactive chemicals e.g. nitric oxide (NO), reactive oxygen species (ROS), and UV irradiation according to Stoffels et al. ${ }^{(9)}$.

Figure 3, indicates clear intensity level of highly reactive radicals such as $\mathrm{OH}$ and $\mathrm{O}$ which playing an important role in damage of cancer cells. One of the mechanisms of apoptosis induction is the DNA damage which is confirmed practically by histopathological investigations. The damage can also be induced due to formation of hydrogen peroxide $\left(\mathrm{H}_{2} \mathrm{O}_{2}\right)$. A hydrogen peroxide molecule, may pass through cell membrane and causes lethal effects such as fatal damage for DNA. This was found according to the results obtained by Imlay et al., ${ }^{(20)}$.

In the Ehrlich tumor model, plasma treatment shows a significant reduction of tumor volume at the end of the treatment period, as compared to control.

These data are in agreement with those obtained by Keidar et al., Keidar et al. and walk et al. ${ }^{(5,20,21)}$.

Finally PCAP shows an increase of $46 \%$ of mice life span, and increase in survival period of the animals which reflects a high cytotoxic effect for tumor when it is treated with cold plasma.

\section{Conclusion}

- The present study demonstrates a marked antitumor effect of plasma treatment for Ehrlich carcinoma with a significant decrease of tumor volume.

- Plasma treatment lead to enhancement of mice survival interval for treated objects with plasma jet comparing to control group.

- The obtained results indicate that the present therapeutic method may deliver reactive oxygen species (ROS) directly into tumor cells.

- The present results are very promising and highlight the potential of plasma jet treatment as an anticancer inhibitor with little or no toxic side effects.

\section{References}

1. Cooper, M., Fridman, G., Staack, D., Gutsol, A.F., Vasilets, V.N., Anandan, S., Cho, Y.I., Fridman, A. and Tsapin, A., "Decontamination of Surfaces From Extremophile Organisms Using Nonthermal Atmospheric Pressure Plasmas", IEEE Trans. Plasma Science, 37, 866-871, (2009).

2. Laroussi, M. and Lu, X., Room-temperature atmospheric pressure plasma plume for biomedical applications, Applied Phys. Letters, 87, 113902, (2005).

3. Fridman, G., Shekhter, A.B., Vasilets, V.N., Friedman, G., Gutsol, A. and Fridman, A.," Applied Plasma Medicine", Plasma Process and Polymers, 5, 503-533, (2008). 
4. Kim, C.-H., Kwon, S., Bahn, J.H., Lee, K., Jun, S.I., Rack, P.D. and Baek, S.J., Effects of atmospheric nonthermal plasma on invasion of colorectal cancer cells. Appl. Phys. Lett. 96, 243701, (2010a).

5. Keidar, M., Walk, R., Shashurin, A., Srinivasan, P., Sandler, A., Dasgupta, S., Ravi, R., Guerrero-Preston, R., and Trink, B., Cold plasma selectivity and the possibility of a paradigm shift in cancer therapy, Brit. J. Cancer, 105, 1295 - 1301, (2011).

6. Vandamme, M., Robert, E., Lerondel, S., Sarron, V, Ries, D., Dozias,S., Sobilo, J., Gosset, D., Kieda, C., Legrain, B., Pouvesle, J.M. and Pape, A.P., ROS implication in a new antitumor strategy based on non-thermal plasma, Int. J. Cancer, 130, 21852194, (2011).

7. Fridman, G., Shereshevsky, A., Jost, M. M., Brooks, A. D.,Fridman, A., Gutsol, A., Vasilets, V. and Friedman, G., Floating electrode dielectric barrier discharge plasma in air promoting apoptotic behavior in melanoma skin cancer cell lines, Plasma Chem. Plasma Process, 27, 163-176, (2007).

8. Stoffels, E., Kieft, I. E., Sladek , R . E. J., van den Bedem , L . G. M.,van der Laan, E. P. and Steinbuch, M., Plasma needle for in vivo medical treatment: recent developments and perspectives, Plasma Sources Sci. Technol. 15,169-180 (2006).

9. Stoffels, E., Sakiyama, Y. and Graves, D.B., Cold atmospheric plasma: Charged species and their interactions with cells and tissues, IEEE Trans. Plasma Sci. 36, 1441-1457 (2008).

10. Ozaslan, M., Karagoz, I. D., Kilic, I. H. and Guldur, M. E., Ehrlich ascites carcinoma. J. Biotechnol. 10(13), 2375-2378 ( 2011).

11. Shaker, M. N., Ramadan, H. S., Mohamed, M. M., Khatib, A. M. and Roston, G. D., Enhanced photodynamic efficacy of PLGA-encapsulated 5-ALA nanoparticles in mice bearing Ehrlich ascites carcinoma. Applied Nanoscience, 4, 777-789 (2013).

12. García-Alcantara, E., López-Callejas, R., Morales-Ramírez, P. R., Peña-Eguiluz, R., Fajardo-Muñoz, R., Mercado-Cabrera, A. and Rojas-Olmedo, I. A., Accelerated mice skin acute wound healing in vivo by combined treatment of argon and helium plasma needle. Archives of Medical Research, 44(3), 169-177 (2013).

13. Dong, L., Ji, Y., Liu, W., Chen, J. and Yang, Y. Diagnostics and application of an atmospheric pressure plasma generated with a hollowneedle-plate dielectric barrier discharge. IEEE Transactions on Plasma Science, 40(6 PART 2), 1701-1706,(2012).

14. Humud H.R., Wasfi A.S. , Abd Al-Razaq W. and El-Ansary M.S. Argon plasma needle source. Iraqi Journal of Physics, 10 (17), PP. 53-57, (2012).

15. Klein, G. and Revesz, L., Quantitative studies on the multiplication of neoplastic cells in vivo. I. growth curves of the Ehrlich and MC1M ascites tumors", J. Natl. Cancer Inst. 14, 229 (1953). 
16. Elbialy, N., Abdelhamid, M. and Youssef, T., Low power argon laser induced thermal therapy for subcutaneous ehrlich carcinoma in mice using spherical gold nanoparticles, J. Biomed. Nanotechnol, 6, 1-7 (2010).

17. Kabel, A. M., Effect of combination between methotrexate and histone deacetylase inhibitors on transplantable tumor model, American Journal of Medicine Studies, 2, 12-18 (2014).

18. Dobrynin, D., Fridman, G., Friedman, G. and Fridman, A., Physical and biological mechanisms of direct plasma interaction with living tissue. New J. Phys. 11,1-26 (2009)

19. Walk, R. M., Snyder, J. a., Srinivasan, P., Kirsch, J., Diaz, S. O., Blanco, F. C. and Sandler, A. D., Cold atmospheric plasma for the ablative treatment of neuroblastoma. Journal of Pediatric Surgery, 48(1), 67-73 (2013).

20. Imlay, J., Chin, S. and Linn, S. "Toxic DNA damage by hydrogen peroxide through the Fenton reaction in vivo and in vitro" Science 240, 640-642 (1988).

21. Keidar, M., Shashurin, A., Volotskova, O., Ann Stepp, M., Srinivasan, P., Sandler, A. and Trink, B. Cold atmospheric plasma in cancer therapy. Physics of Plasmas, 20(5), 1-8 (2013).

(Received18/5/2015

accepted $18 / 10 / 2016$ ) 
تأثير البلازما الباردة على سرطان الإرليك

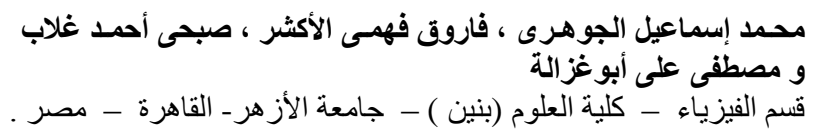

أدى التقدم الحديث فى بلازما الضغط الجوى إلى تخليق بلازما باردة بدرجة

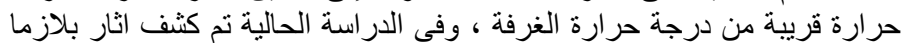

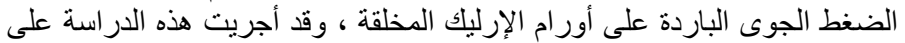

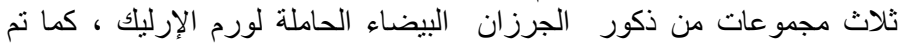

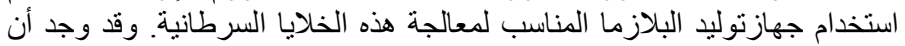

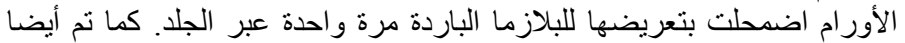

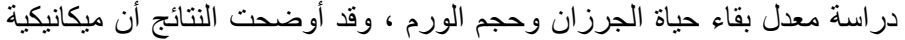

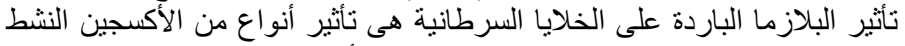

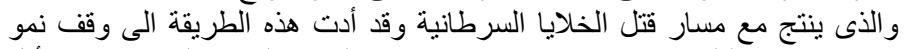
خلايا ورم الإرليك وتعتبر طريقة جديدة ومتطورة لعلاج الخلايا السرطانية مع أقل

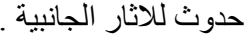

